Derecho y Realidad

Vol.13 -Núm. 26 • Julio-Diciembre de 2015

Págs. 185-206• ISSN:1692-3936

\title{
Derecho al trabajo de las mujeres en situación de desplazamiento del municipio de Facatativá*
}

\author{
Right to work of displaced women of Facatativá
}

\author{
Ángela Consuelo Vega Vaca**
}

\section{Resumen}

La problemática del desplazamiento forzado en Colombia ha tomado importancia a lo largo del tiempo, gracias a las diferentes luchas que se han desarrollado por parte de sus actores directos. En especial de las mujeres en quienes recae la responsabilidad directa del sostenimiento económico y emocional de sus familias en el momento de la vida en que ocurre el desplazamiento. Dentro de esas estrategias, ellas recurren inicialmente al Estado para obtener ayudas de carácter urgente y más adelante exigir que sean respetados sus derechos económicos y sociales, vulnerados directa o indirectamente por los agentes del Estado, al no garantizar la seguridad y el respeto de su ciudadanía en el medio en el que se venían desenvolviendo cotidianamente, y al exponerse a un sin número de actividades propias de la ciudad para la generación de ingresos que, en este contexto, no garantizan el derecho al trabajo consignado en documentos nacionales e internacionales.

Fecha de aceptación: 26 de abril de 2015

Concepto de recepción: 29 de febrero de 2016

Fecha de aprobación: 15 de noviembre de 2015

* Artículo resultado del proyecto de investigación "Derecho al trabajo de las mujeres en situación de desplazamiento del municipio de Facatativá“. Este artículo es producto de una monografía para optar por el título de Magister en Derechos Humanos. UPTC. Bogotá. 2015.

** Trabajadora Social de la Universidad Colegio Mayor de Cundinamarca. anconvega@gmail.com. 


\section{Palabras clave}

Desplazamiento, mujer, Estado, derechos humanos, trabajo.

\section{Abstract}

The problem of the forced displacement in Colombia has taken importance over time due to the different struggles of their direct actors. Especially for women who have the direct responsibility for the economic and emotional support of their families at the time of life at which displacement takes place. Within these strategies they initially go to the State to get urgent aid and later demand that their economic and social rights directly or indirectly are violated by agents of the State, by not guaranteeing security and respect for their citizenship in the space where they had a daily basis, and being exposed to a number of activities of the city to get some money that, in this context, do not guarantee the right to work set in national and international documents.

\section{Keywords}

Displacement, human rights, women, State, work.

\section{Sumario}

1. Introducción

2. Desplazamiento y mujer desplazada en Facatativa

3. Resultados

4. Conclusiones

5. Referencias 


\section{Método}

Empírico Sociológico.

\section{Metodología}

Este artículo se genera a partir de la investigación realizada dentro de un proceso académico, con el fin de conocer la realización de la garantía del derecho al trabajo de las mujeres en situación de desplazamiento del municipio de Facatativá.

La investigación se plantea desde el método cualitativo, en cuanto a consideraciones teóricas -el cual se focaliza en los derechos humanos desde una perspectiva crítica-, técnicas e instrumentos, estrategias y procesamiento de la información. En la investigación se utilizó una aproximación fenomenológica, "teniendo en cuenta la intención de describir los significados en los que se encuentra inmerso el ser humano en la cotidianidad" (Rodríguez, 1998). Entre las corrientes de la fenomenología se escogió trabajar la corriente hermenéutica, la cual trata de comprender la realidad social a través de la interpretación de lo expresado por medio del lenguaje oral o escrito de las personas que vivencian la situación.

Dicho análisis se desarrolló bajo el establecimiento de revisiones del estado actual de la población en situación de desplazamiento en Colombia y Cundinamarca, la normatividad y parámetros nacionales con relación al tema de derechos y vulnerabilidades de la población desplazada, la revisión conceptual de las variables de género, trabajo y desplazamiento y su relación tanto con derechos humanos como con el derecho especifico al trabajo; al igual que las estrategias empleadas tanto a nivel nacional como territorial de Ios lineamientos para la atención y restablecimiento de los derechos de las personas desplazadas, concretamente de las mujeres, en Facatativá.

Lo anterior se adelantó mediante el acercamiento, la observación y comunicación con las integrantes de una de las asociaciones de desplazados que se encuentran en el municipio de Facatativá, la Asociación Nuevo Comienzo, para determinar su percepción frente a la garantía que se da en el municipio al derecho al trabajo para las mujeres en situación de desplazamiento. Por lo cual se inscribe en la esfera de lo cualitativo, lo que implicó una observación detallada sobre su funcionamiento y estructura, entrevistas a algunas mujeres, asistir a las reuniones, crear espacios propicios para las conversaciones informales. 
Para el desarrollo del trabajo se utilizó la investigación social participativa, teniendo en cuenta que este tipo de trabajo brinda la posibilidad de seguir un proceso que respeta la visión que tienen las mujeres desplazadas, sobre los problemas y situaciones que las afectan, y abre la posibilidad de recoger, identificar y racionalizar necesidades. Como mencionan Kemmis y Mc Taggart, la investigación social participativa es "una forma de indagación introspectiva colectiva emprendida por participantes en situaciones sociales con objeto de mejor racionalidad y justicia de sus prácticas sociales, así como la comprensión de esas prácticas y de las situaciones en que estas tienen lugar" (Kemmis \& Mc Taggart, 1998, p. 9)

Este tipo de investigación implica un estudio reflexivo de un fenómeno social en el contexto en el que se produce, es decir, la situación se estudia mientras las personas están viviendo su impacto. Por lo cual se quieren identificar las diferentes vivencias y las impresiones que las mujeres desplazadas al insertarse en un contexto específico, tienen acerca de un derecho como es el trabajo.

El análisis inicia con el cruce entre la teoría y la información que se recoge de las mujeres desplazadas del municipio, teniendo en cuenta un conocimiento preliminar de la situación de las personas en general desplazadas dentro de Facatativá, para tener una visión más clara de estrategias y recursos a nivel institucional y estatal con los que cuenta la mujer en el momento de llegar a esta ciudad. Este análisis se desarrolla mediante la indagación de procesos y requisitos tanto en la Secretaría de Gobierno como en la Personería Municipal para el acceso a cada uno de los servicios que tiene la población desplazada al momento de su llegada.

Durante el proceso de campo se realiza la caracterización de las personas integrantes de la asociación, y su situación actual, por medio de la aplicación de encuestas generales. Sin embargo, para profundizar en el tema del derecho al trabajo, se toma igualmente como base la encuesta pero se amplía cada una de las preguntas por medio de entrevistas grupales ${ }^{1}$, con el fin de reflexionar y entender la percepción que tiene cada una de las integrantes de la asociación con respecto al trabajo y su garantía en el municipio. Estas sesiones permiten recoger las impresiones y percepciones de las integrantes del grupo frente a los temas de la investigación, identificando opiniones acerca de género, derechos humanos, trabajo, trabajo digno y derecho al trabajo. 


\section{Introducción}

EI desplazamiento forzado en Colombia se ve ligado a una variedad de condiciones de desigualdades sociales, políticas y económicas, las cuales se evidencian en pobreza y falta de garantías estatales para el desarrollo equitativo de sus habitantes. Son preocupantes las cifras de desplazados en Colombia, pues actualmente, según reporte establecido por Codhes, de 1985 al 2013 el número de desplazados se podía establecer en 5.921.229 víctimas, "Colombia continúa siendo el país con más desplazados en el mundo sólo comparable con la situación de Siria, donde se calcula entre 4,25 y 6 millones de personas y muy por encima de El Congo (3 millones), Sudán (2 millones 445.000) o Iraq (entre 2 y 2,84 millones)" (Codhes, 2013, p. 3).

En Colombia habita un número aproximado de 23`312.832 mujeres, según el Departamento Administrativo Nacional de Estadísticas, de las cuales 2'592.500, son víctimas de desplazamiento forzado desde 1996, equivalente al $51 \%$ del total de la población afectada por este hecho victimizante (Acnur, 2012). Las mujeres, en el contexto del conflicto armado, se enfrentan a factores de riesgo y vulnerabilidades específicas que afectan el pleno ejercicio de los derechos constitucionales. Estas vulnerabilidades son reconocidas por la Corte Constitucional a raíz del Ilamamiento de la Comisión Interamericana de Derechos Humanos, que se refleja en la declaración del "Estado de cosas inconstitucional" y específicamente con el Auto 092, en donde se establecen situaciones en las cuales se manifiesta la vulnerabilidad de la mujer frente al hombre. La mujer desplazada, por el hecho de ser mujer, se enfrenta a una mayor vulneración de sus derechos como sobreviviente del desplazamiento, como lo referencia Codhes.

Ellas reciben un mayor impacto como sobrevivientes en tanto que sufren por la desaparición de sus seres queridos, deben enfrentar la lucha cotidiana para volver a empezar y mantienen la gran incertidumbre por el presente inmediato y el futuro. De manera abrupta se constituyen, en muchos casos, en únicas proveedoras económicas y afectivas de estos hogares que, forzosamente, se convierten en monoparentales. (1999, p. 62)

Estas mujeres son personas provenientes de escenarios contrarios a los de la ciudad, con ritmos y vivencias diferentes, en donde, a pesar de lo que han vivido, continúan aferrándose a la esperanza de construir un camino sin violencia para ellas y sus hijos, en un lugar ajeno a su cotidianidad. Buscan la solidaridad de una ciudad permeada por el capitalismo, en la que prevalece la individualidad aprendida, y a pesar de eso, con grandes esfuerzos, tiempo y vivencias se construyen redes de soporte para el avance, progreso y establecimiento de formas de supervivencia. 
Concretamente, en el caso del derecho al trabajo y su garantía, estas mujeres al llegar no se desenvuelven al mismo ritmo de la ciudad y en ocasiones desconocen las formas de acceder a programas de vinculación laboral, capacitación, o acceso a formas productivas para la obtención de recursos económicos, lo que les obstaculiza de manera significativa el acceso a un trabajo adecuado o a las opciones productivas que les ofrecen los programas institucionales del Estado. Estas mujeres se enfrentan al rechazo continuo al no tener en muchos casos experiencia comprobada en el oficio que pretenden desempeñar, o no tener referencias en la ciudad en la que se ubiquen que corroboren que son personas confiables, o incluso por la poca escolaridad con la que Ilegan a la nueva ciudad, lo cual hace que sus opciones laborales se encaminen hacia el comercio informal de elementos o productos que ellas mismas elaboran, o a la compra y comercialización de productos elaborados.

En términos de sus características, estas mujeres que en su contexto antes del desplazamiento se dedicaban a labores domésticas como cocinar para su familia y en ocasiones para obreros, cuidar y estar pendientes de sus hijos, y apoyar a su pareja en labores de campo para una estabilidad económica y familiar, otras además representaban un papel de lideresas dentro de sus comunidades, con reconocimiento por parte de quienes lideraban lo que pudo llevar a ese desplazamiento repentino pero anunciado. Roles que independientemente de sus condiciones y vivencias se reflejan en el momento de Ilegada a la ciudad o municipio receptor.

Las mujeres desplazadas en el lugar de Ilegada refleja conocimientos rurales, como por ejemplo la vinculación a sectores agrícolas como la floricultura, el servicio en fincas ya sea para desempeñar labores campesinas o para la atención de obreros y patrones en área doméstica, y en el mejor de los casos la vinculación como operarias o en servicios generales en empresas productoras del sector (Meertens, 2000, p. 12).

Por otra parte, para dar respuesta a la necesidad de subsistencia y empleo de las mujeres desplazadas, el Estado sin un análisis profundo genera estrategias dentro de una filosofía neoliberal, en donde lo que se busca es incluir a la mujer desplazada en formas de producción y de reproducción del capital, mediante la capacitación en labores mecánicas, operativas y sin ningún tipo de formación reflexiva y acorde a sus expectativa, que conducen a que ellas se inserten en el nivel más bajo de la escala productiva, el operativo, como fuerza de trabajo barata, sin que esto lleve a que ellas sientan que se está satisfaciendo su derecho al trabajo, ni que se les están proporcionando oportunidades de mejoramiento de su calidad de vida acorde con sus características como mujeres y de ser desplazadas. A pesar de que se consideran afortunadas al haber encontrado trabajo relativamente estable, en el caso en que son empleadas de manera formal, o que su forma de generar recursos satisface sus necesidades. 
Pero para "Ias mujeres que se involucran en dichos procesos y estrategias institucionales no es evidente que dichas acciones tengan repercusiones positivas en sus proyectos de vida y en su estabilización socioeconómica para el mejoramiento de su calidad de vida". (Meertnas, 2000, p. 12). Acciones y lineamientos en los que, según parámetros nacionales y municipales, tienen prevalencia las personas en situación de desplazamiento. A pesar de esto, las mujeres continúan identificando falencias en la garantía de su derecho al trabajo.

Es así como, a nivel general nacional, departamental y territorial, no se han formulado programas que respondan específicamente a las necesidades de las mujeres desplazadas, ya que son incluidas en programas regulares diseñados para población vulnerable, que no responden ni a las expectativas, capacidades, aprendizajes y cultura con los que Ilegan, ni al posible desenvolvimiento en la ciudad. Lo que ha llevado, según estas mujeres, a que se repita y perpetúe la discriminación y el trabajo informal, que no permiten cubrir las necesidades básicas de las familias de las mujeres desplazadas. "La ausencia de una política específica para garantizar el acceso justo y equitativo de las mujer a la oferta laboral ha llevado a que se perpetúen las formas de discriminación de inserción de las mujeres en la competencia para la obtención de recursos que permitan su auto sostenimiento y el de sus familias." (Observatorio de Derechos Humanos, 2000, p. 25)

Este círculo vicioso representa la inoperatividad de los sectores del Estado al no garantizar que a los derechos de las mujeres desplazadas se le reconozca su importancia para el desarrollo del país. No se reconoce la deuda social que tiene el Estado con esta población; además, no se invierte lo verdaderamente necesario económicamente en los programas de estabilización para las mujeres desplazadas, y no se reconoce la prioridad que debe tener la mujer dentro de estas inversiones para una verdadera estabilización socioeconómica, sino, al contrario se le ofrece una simple atención paliativa en estos momentos. Todo lo cual indica que se requiere de mayor atención a este numeroso grupo de personas y a esta problemática en el país.

\section{Metodología de la investigación}

Este artículo se genera a partir de la investigación realizada dentro de un proceso académico, con el fin de conocer la realización de la garantía del derecho al trabajo de las mujeres en situación de desplazamiento del municipio de Facatativá.

La investigación se plantea desde el método cualitativo, en cuanto a consideraciones teóricas -el cual se focaliza en los derechos humanos desde una perspectiva crítica-, técnicas e instrumentos, estrategias y procesamiento de la información. En la investigación se utilizó una aproximación fenomenológica, "teniendo en cuenta la intención de describir los significados en los que se encuentra inmerso el ser humano 
en la cotidianidad" (Rodríguez, 1998). Entre las corrientes de la fenomenología se escogió trabajar la corriente hermenéutica, la cual trata de comprender la realidad social a través de la interpretación de lo expresado por medio del lenguaje oral o escrito de las personas que vivencian la situación.

Dicho análisis se desarrolló bajo el establecimiento de revisiones del estado actual de la población en situación de desplazamiento en Colombia y Cundinamarca, la normatividad y parámetros nacionales con relación al tema de derechos y vulnerabilidades de la población desplazada, la revisión conceptual de las variables de género, trabajo y desplazamiento y su relación tanto con derechos humanos como con el derecho especifico al trabajo; al igual que las estrategias empleadas tanto a nivel nacional como territorial de los lineamientos para la atención y restablecimiento de los derechos de las personas desplazadas, concretamente de las mujeres, en Facatativá.

Lo anterior se adelantó mediante el acercamiento, la observación y comunicación con las integrantes de una de las asociaciones de desplazados que se encuentran en el municipio de Facatativá, la Asociación Nuevo Comienzo, para determinar su percepción frente a la garantía que se da en el municipio al derecho al trabajo para las mujeres en situación de desplazamiento. Por lo cual se inscribe en la esfera de lo cualitativo, lo que implicó una observación detallada sobre su funcionamiento y estructura, entrevistas a algunas mujeres, asistir a las reuniones, crear espacios propicios para las conversaciones informales.

Para el desarrollo del trabajo se utilizó la investigación social participativa, teniendo en cuenta que este tipo de trabajo brinda la posibilidad de seguir un proceso que respeta la visión que tienen las mujeres desplazadas, sobre los problemas y situaciones que las afectan, y abre la posibilidad de recoger, identificar y racionalizar necesidades. Como mencionan Kemmis y Mc Taggart, la investigación social participativa es "una forma de indagación introspectiva colectiva emprendida por participantes en situaciones sociales con objeto de mejor racionalidad y justicia de sus prácticas sociales así como la comprensión de esas prácticas y de las situaciones en que estas tienen lugar" (Kemmis \& Mc Taggart, 1998, p. 9)

Este tipo de investigación implica un estudio reflexivo de un fenómeno social en el contexto en el que se produce, es decir, la situación se estudia mientras las personas están viviendo su impacto. Por lo cual se quieren identificar las diferentes vivencias y las impresiones que las mujeres desplazadas al insertarse en un contexto específico, tienen acerca de un derecho como es el trabajo.

El análisis inicia con el cruce entre la teoría y la información que se recoge de las mujeres desplazadas del municipio, teniendo en cuenta un conocimiento preliminar 
de la situación de las personas en general desplazadas dentro de Facatativá, para tener una visión más clara de estrategias y recursos a nivel institucional y estatal con los que cuenta la mujer en el momento de llegar a esta ciudad. Este análisis se desarrolla mediante la indagación de procesos y requisitos tanto en la Secretaría de Gobierno como en la Personería Municipal para el acceso a cada uno de los servicios que tiene la población desplazada al momento de su Ilegada.

Durante el proceso de campo se realiza la caracterización de las personas integrantes de la asociación, y su situación actual, por medio de la aplicación de encuestas generales. Sin embargo, para profundizar en el tema del derecho al trabajo, se toma igualmente como base la encuesta pero se amplía cada una de las preguntas por medio de entrevistas grupales ${ }^{1}$, con el fin de reflexionar y entender la percepción que tiene cada una de las integrantes de la asociación con respecto al trabajo y su garantía en el municipio. Estas sesiones permiten recoger las impresiones y percepciones de las integrantes del grupo frente a los temas de la investigación, identificando opiniones acerca de género, derechos humanos, trabajo, trabajo digno y derecho al trabajo.

\section{Desplazamiento y mujer desplazada en Facatativá}

Para el análisis de la situación de la población víctima del conflicto armado en Facatativá, específicamente las mujeres en situación de desplazamiento que se encuentran asentadas en este municipio, dentro de la investigación planteada y como parte importante dentro del contexto social y normativo, se toman como base dos documentos específicos. El primero es La política pública social de derechos de las familias Facatativeñas y sus integrantes con y sin discapacidad, el cual abarca de manera general los lineamientos para el accionar de las diferentes administraciones a partir del año 2012 al año 2025, cuando debe ser revisada y reformulada.

Esta política pública es transversal a todos los ciclos vitales y poblaciones habitantes en el municipio, y hasta el momento no se han formulado políticas públicas de atención diferencial como para la población en situación de desplazamiento. Igualmente, el tema de género se inserta a la política pública, a los programas y acciones de manera superficial e independiente, sin tener en cuenta la transversalidad y la profundidad que implica el enfoque de género en todas las acciones que se desarrollen en el municipio, al tener una representación del 50.2 \% de mujeres.

\footnotetext{
Entrevista grupal, como espacio de interacción y diálogo con un número reducido de participantes entre seis y diez personas, para facilitar la activa participación de todos en torno a preguntas específicas, ante las cuales el investigador procurará que todos se pronuncien.
} 
En el tema de productividad y empleo, igualmente se hace referencia de manera general en cuanto a beneficio de toda la población en la política pública, con el establecimiento de un

plan de ofertas y oportunidades con el cual se apoya a las familias más vulnerable en la consecución de empleo o en el desarrollo y/o fortalecimiento de unidades productivas que permitan generar ingresos para asegurar alimentariamente a la familia, especialmente a los niños y niñas, a las madres gestantes, a la población en condición de discapacidad y a los adultos mayores. (Alcaldia Municipal de Facatativá, 2011, p. 56)

En el aparte de productividad, la política establece que en Facatativá se debe establecer como prioridad la productividad y el emprendimiento, para generar desarrollo sostenible y disminuir la pobreza y mejorar niveles de calidad de vida en el sector rural y urbano. En un segundo plano se establece que "para que se genere desarrollo local y mejorar la calidad de vida, las familias facatativeñas deberán acceder a la posibilidad de empleo digno y decente" (Alcaldia Municipal de Facatativaá, 2011), a través de estrategias de consecución de empleos, pero no empleos con condiciones dignas para las personas que habitan en el municipio, sino enfocado principalmente en la generación de ventajas para las empresas que ingresen al municipio, como incentivo de puestos de trabajo, "todos sus actores públicos y privados... deberán generar ventajas competitivas y comparativas, tanto en infraestructura... que hagan de Facatativá un municipio atractivo para la inversión y atraiga grandes empresas" (Alcaldía de Facatativá, 2013).

Lo anterior deja en evidencia que la política pública es muy general en el ámbito de su población, a pesar de los distintos esfuerzos a nivel nacional por la generación de lineamientos para la atención diferencial de los grupos poblacionales. $Y$ lo que busca es establecer estrategias para la implementación de acciones que beneficien a la población sin hacer énfasis en un grupo poblacional específico, pero, de igual manera, hasta la fecha el municipio no cuenta con políticas públicas que manejen problemáticas o grupos poblacionales determinados, como mujeres, niños, población en situación de desplazamiento, juventud, adulto mayor y otros. Procesos que se deben establecer para la atención diferencial y para la superación de inequidades en la comunidad.

EI "Plan de atención territorial para la prevención, asistencia, atención y reparación integral a las víctimas del conflicto armado en el municipio de Facatativá" formulado en el año 2013, recoge las estrategias para la prevención, atención y reparación de las personas víctimas del conflicto armado en Facatativá, y es la base para la formulación de la política pública para las víctimas del conflicto armado. Y en el plan de desarrollo "Todos Somos Facatativá 2012- 2015", en los capítulos en los 
que se hace referencia a la atención de la población víctima del conflicto armado de manera transversal en todos los programas de la Administración.

Tomando como base la documentación anterior, se establece que Facatativá se ha consolidado, históricamente, más como un municipio receptor que como un municipio expulsor dentro de la dinámica del conflicto armado. Esta ciudad se ha estructurado como uno de los municipios de Cundinamarca con gran número de personas desplazadas, después de Soacha, debido a las opciones laborales que hay para la población que habita en ella, en empresas como Yanbal, Bio D. S.A, Alpina, Alimentos Polar, Ecopetrol, Arrocera de la Sabana, Empresa Raza, Inagro, y por la cercanía geográfica con Bogotá y Soacha. Presentándose con mayor regularidad como uno de los sitios importantes para el paso y asentamiento de las mujeres desplazadas de diferentes lugares del país, principalmente del eje cafetero.

Facatativá, debido a su situación geográfica ubicada al extremo de la Sabana Occidente y con una gran influencia sobre esta margen del departamento de Cundinamarca, es preponderantemente receptor de población víctima del desplazamiento forzado, la cual se ha venido incrementando en los últimos años. (Alcaldía de Facatativá, 2013, p. 7)

En el caso de la población femenina, existe mayor receptividad en los cultivos de flores, por lo cual, "la población en situación de desplazamiento, femenina ( $\mathrm{sic}$ ) en Facatativá es significativamente más representativa en este sector del cultivo de flores que en empresas de producción del municipio" (Alcaldía de Facatativá, 2013). Igualmente, por las condiciones antes descritas en relación con las condiciones de desplazamiento a nivel general en el país, ya que Facatativá cuenta con una enorme cantidad de empresas dedicadas a la floricultura (popularmente se les conoce como "floras"), actividad que es, quizá, la que más ciudadanos emplea.

Las cifras que se manejan de población en situación de desplazamiento en Facatativá, se consolidan gracias a la caracterización realizada en el mes de abril de 2014 por la Secretaría de Gobierno del municipio donde se identifican 6.840 personas víctimas del conflicto armado constituidas en 2150 familias, que presentan como hecho victimizante el desplazamiento en su totalidad o, al menos, así lo declaran (Alcaldía de Facatativá, 2013).

El municipio presenta una característica especial que contradice o se encuentra fuera de las estadísticas nacionales, al evidenciar que el $49 \%$ de las personas desplazadas son mujeres, y el $51 \%$ son hombres (Alcaldía de Facatativá, 2013). Hay que anotar que esta variable es diferente al resto del país, pero sin dejar de identificar las mismas problemáticas que en otros sectores, como son la jefatura de hogar en una gran número de familias, la responsabilidad del sustento familiar que 
recae sobre la mujer, la viudez, las experiencias violentas por las que pasaron, entre otras (Alcaldía de Facatativá, 2013).

Con respecto a la productividad, se identifica que las opciones de acceder a proyectos productivos que, como se consagra en el Decreto 250 de 2005, son derechos de cada una de las personas desplazadas en Colombia, no tienen el suficiente peso, por lo cual, al igual que otros muchos programas no tienen las facilidades para que la población desplazada acceda a ellos, y se desarrollan para la población vulnerable en general sin tener en cuenta características y precisiones para la población desplazada.

Otro documento es el "Plan de acción territorial para la prevención, atención, asistencia y reparación integral a las víctimas del conflicto armado en el municipio de Facatativá", que consigna las acciones y estrategias para el goce efectivo de los derechos de las personas en situación de desplazamiento, que se encuentren asentadas en el municipio de Facatativá.

Uno de los objetivos que se contemplan en el plan de acción antes mencionado, es el de "Restablecer los derechos vulnerados como consecuencia del conflicto armado, en un marco democrático, participativo y equitativo" (Alcaldía de Facatativá, 2013). Para lo cual el municipio depende directamente de la nación tanto en recursos como para la tramitología de garantía de derechos, por eso en el municipio es complejo el reconocimiento de priorización de derechos específicos como la garantía del acceso a vivienda, obtención de ayudas humanitarias, prórrogas y derecho al trabajo, y con ello, de desarrollo de ofertas para la población desplazada y mujeres con mayor relevancia, además de la poca importancia que para la Administración de turno genera esta problemática.

En cuanto a productividad y empleo, en el plan de acción los integrantes del Comité Territorial de Justicia Transicional reconocen que "El derecho al trabajo es uno de los derechos más vulnerados a la población víctima, se identifica que el común denominador es el desempleo, que obliga a muchas familias a asegurar su existencia a través de la economía informal." (Alcaldía de Facatativá, 2013). Es así como se reconoce desde la institucionalidad y en el común de la población de Facatativá, que este derecho necesita atención prioritaria y permanente para el logro de otros derechos asociados a él, pero que por parte de entes nacionales, departamentales y municipales su atención es invisibilizada y subvalorada.

Este plan establece que "el municipio a través de la Secretaría de Desarrollo Económico y la Dirección Agropecuaria, cuenta con programas y proyectos productivos para lograr la estabilización socioeconómica y generación de ingresos económicos, con el acompañamiento de la Gobernación de Cundinamarca dirigidos a la población urbana y rural" (Alcaldía de Facatativá, 2013). Esta estrategia, 
como se menciona en líneas anteriores, cobija de igual forma población en general sin tener en cuenta la vulnerabilidad agravada que implica el hecho de ser persona en situación de desplazamiento habitante del municipio, y que no subsana la gran problemática que se evidencia en la población en situación de desplazamiento y de las mujeres que representan la jefatura de estas familias

Así mismo, la Secretaría de Desarrollo Económico cuenta con un programa del Banco de Empleos, "en donde se reciben y recepcionan (sic) las hojas de vida para identificar con la víctima sus necesidades particulares, sus habilidades y conocimientos para detectar las posibles alternativas de subsistencia digna y autónoma a las que pueda acceder a un trabajo digno" (Alcaldía de Facatativá, 2013). Trabajo que, por lo general y teniendo en cuenta las características de las mujeres en situación de desplazamiento, será el de un cultivo de flores, que en muchos casos no garantiza estabilidad, horarios legales ni garantías de trabajo digno para una persona, por lo cual esta población pierde credibilidad en estas opciones de empleo, y se ve obligada a buscar la generación de ingresos en otros lugares, por cuenta propia.

En muchos casos, la estrategia ni siquiera es vincularlas laboralmente de manera formal, sino que lo que se busca es que la población en situación de desplazamiento formule proyectos productivos en donde se requiere ingresar a una vida crediticia, para la cual no tiene la capacidad económica y tampoco la práctica. En efecto, el Plan afirma que esta estrategia se contempla, con el fin de que "Ios hogares en situación de desplazamiento ubicados en Facatativá dispongan de al menos una fuente de ingresos autónoma que les permita condiciones de vida por encima de la línea de pobreza" (Alcaldía Municipal de Facatativá, 2011). Todo lo anterior conduce a esta población desplazada a diversas situaciones que hacen aún más difícil su supervivencia en la ciudad, ya que en el momento en que empieza a evidenciar el bajo rendimiento económico de su inversión y el aumento continuo de los intereses y por ende del crédito, hace que se recurra nuevamente al subempleo y a la informalidad con un sentimiento de frustración y desamparo del Estado ante su situación, y, para colmo de males, con una deuda que deben pagar.

\section{Resultados}

El desplazamiento forzado por la violencia es el escenario donde de cierta manera confluyen los roles de victima (indirecta) de la violencia (la viudez, la jefatura femenina del hogar, el trauma, la extrema pobreza en la ciudad) y de protagonista, si no del espacio público, por lo menos de su propio proyecto de vida. Entre múltiples organizaciones urbanas que han surgido en torno a pequeños proyectos de supervivencia económica o en defensa de los derechos humanos, se perfila cada vez más la participación femenina con un tema unificador, el de la tolerancia y la convivencia pacífica. (Meertens, 2000, p. 30) 
En el transcurso de la investigación y como resultado, luego de la recopilación de la información, su análisis y su contraste con los diferentes documentos que existen sobre desplazamiento, y los derechos de las mujeres en situación de desplazamiento, así como la normatividad, se puedo establecer que:

La asociación de mujeres desplazadas "Nuevo Comienzo", se encuentra constituida por 22 mujeres desplazadas, pero para la investigación se trabajó con 16 mujeres, que sustentan la situación de desplazamiento. Ellas se ubican en edades entre los 20 y los 40 años de edad, es decir, un grupo de población joven y en edad productiva desaprovechada, y a la vez, con hijos menores, quienes se asocian entorno a una necesidad de generar ingresos, y una habilidad común como es la de la confección.

Estas mujeres y sus familias provienen de diferentes departamentos del país, mayoritariamente Antioquia, seguido por Cundinamarca, Magdalena y Santander. Esto se debe principalmente a que los dos primeros departamentos tienen cercanía relativa con Facatativá, además por la facilidad de acceso que hay desde estos departamentos, y porque esta ciudad es vía de ingreso a Bogotá. Dentro de la escolaridad de estas mujeres predomina la básica primaria, seguida por un nivel educativo de bachillerato, debido a su condición de campesinas o de mujeres dedicadas a sus familias con pocas opciones de estudio en su sitio de residencia antes del desplazamiento. Las mujeres que tienen estudios a nivel técnico, tecnológico y universitario es menor, y el número de mujeres sin educación es mínimo.

Las familias de las mujeres de la asociación, se caracterizan por ser extensas, en mayor número viven con sus padres e hijos, sin apoyo de sus parejas. La situación familiar actual no se asimila a las condiciones anteriores al desplazamiento, donde la unión familiar era lo más importante y lo más frecuente, y sus esposos representaban un elemento importante en sus vidas en la estabilidad emocional y económica. Además, por una parte, la carga económica y psicológica la deben asumir las mujeres solas, hecho que aumenta las horas de trabajo y las aflicciones emocionales y físicas, lo cual conduce también a la transferencia de responsabilidades a sus hijos, que antes del desplazamiento eran responsabilidad única de la madre.

Las mujeres que pertenecen a la asociación, en su mayoría, tienen un tiempo de permanencia mayor a tres años en Facatativá, lo que les permite un conocimiento suficiente de la tramitología que existe para el acceso a determinados beneficios, las dinámicas laborales, empresas, requisitos, cumplimiento, los ritmos y situaciones de exigencia de las ayudas que proporciona el Estado por intermedio de la alcaldía, generando juegos de supervivencia para ellas y sus familias. Pero también es un tiempo limitado para la superación de algunas barreras para el acceso a una estabilidad económica que proporciona un trabajo, que permita sentirse útil a la sociedad y 
que aporte a una calidad de vida óptima para ellas y sus familias, dependiendo de sus características propias.

Estas mujeres llegan a Facatativá principalmente porque en el municipio vive un familiar, vecino o amigo cercano o conocido del sitio de procedencia, a quienes acuden por necesidad de protección. Vienen también por el anonimato que les proporciona un municipio intermedio como es Facatativá, y por las vías de acceso. Igualmente, prefieren el municipio por lo que refieren sus conocidos sobre oportunidades de comercio y de trabajo en la zona, y por el apoyo del Estado por la cercanía a Bogotá.

"Las corrientes de desplazamiento se orientan entonces dentro de corrientes migratorias tradicionales, que tienen que ver con vías de comunicación, centros urbanos importantes que posibiliten cierto anonimato y con alguna dinámica importante que ofrezca algunas perspectivas de generación de ingresos" (Osorio, 1999).

Las mujeres entrevistadas relatan la importancia que ellas le dan a la protección de la vida, más que a la propia a la de sus familias, en el momento de tomar la decisión del desplazamiento: "La decisión del desplazamiento en el momento en que nos amenazaron y se llevaron a mi marido fue inmediata porque yo no iba a dejar que nos mataran o que mi hijo al que ya le habían dicho antes que si no nos íbamos nos iban a matar uno por uno, que no se les siguiera escondiendo" $1 \mathrm{y}$ al considerar que vale más estar unidos y vivos, que el hecho de trasladarse y enfrentar adversidades en otro lugar. Esto hace que para ellas sea más fácil el hecho del desplazamiento en lo relacionado con la toma de la decisión y del enfrentarse a los contratiempos que con ello trae la ciudad.

Mientras que, consideran ellas, para los hombres es mucho más difícil el hecho de abandonar su sitio de residencia, ya que ellos son más territoriales y menos recursivos en el momento de las crisis. "Para mí lo primordial en ese momento fue cuidar de mis hijos, yo no iba a dejar que se los llevaran o que me los mataran, por eso busqué a una prima que hace mucho tiempo no veía y me vine, yo sé que esta situación va a ser por un tiempo y que la situación se va a poner buena para nosotros, mi marido sí se quedó y hace como un año no lo veo porque no he bajado hasta allá... Él dice que no sabe qué hacer acá y que trabajó mucho por esa tierra para dejarla botada así como así" ${ }^{2}$. La mujer recurre a estrategias diversas para cuidar de sus hijos y aunque es duro el desplazamiento, tiene muchas veces mayores estrategias de supervivencia que el hombre, debido a su rol de madre y de soporte familiar.

\footnotetext{
Relato de mujer desplazada.

2 Relato de mujer desplazada.
} 
Después de un tiempo de llegada, el cual no es muy largo (cinco a ocho días), la mujer tiene la presión económica de salir a la calle para obtener recursos para la subsistencia diaria. Ella inicia los trámites necesarios ante la alcaldía, con o sin apoyo familiar, al igual que con o sin resultados favorables para su cotidianidad. Más adelante opta por fabricar productos para la venta o por la comercialización de productos de revistas, para luego insertarse en procesos de capacitación y generación de ingresos, en donde se recurre a los beneficios que proporciona el Estado. Es así como el 90 \% de las mujeres entrevistadas, manifiesta que en algún momento desde el desplazamiento han trabajado en oficios varios, el $60 \%$ en flores, y el $40 \%$ en comercialización de algún producto, el $20 \%$ en la producción de elementos o alimentos. "Dentro de tales condiciones los hogares generan estrategias para acomodarse y reproducirse, acudiendo a la combinación de diferentes fuentes de ingresos a modificaciones en la distribución de responsabilidades, al apoyo en redes familiares etc." (Meertens, 2000)

Por consiguiente, las mujeres entrevistadas en Facatativá manifiestan que actualmente no tienen un trabajo que satisfaga sus necesidades básicas, o que la principal fuente de recursos económicos proviene de empleos informales, también que su área laboral se fundamenta en la floricultura que, igualmente, no les proporciona estabilidad. El comercio también se fundamenta como área de sustento, y en última medida recurren a la agricultura como su fuente de ingresos.

Estas mujeres refieren que los trabajos que se generan, al ser temporales no permiten que se proporcionen medios de estabilización y de desarrollo integral para ellas y sus familias, sino que se estancan en un ciclo de trabajo en empresa- desempleo, en el cual se la juegan nuevamente al trabajo temporal, que no les permite superar el estado de vulnerabilidad en el cual se encuentran, "eso dura muy poquito y uno no puede tener algo seguro, entonces uno trabaja por un tiempo y después se queda otra vez sin trabajo, a ver dónde lo reciben otra vez o le toca otra vez ponerse a vender cositas en la calle" (mujer desplazada integrante de la Asociación Nuevo Comienzo).

En la ciudad, la vida familiar representa un reto para ellas, mientras las mujeres se pasan los días buscando la posibilidad de generar un ingreso con el cual puedan suplir sus necesidades básicas, sus hijos se encuentran conociendo y reconociendo las diferentes posibilidades -buenas o malas- que les proporciona la ciudad y que al momento de la llegada les genera un atractivo por descubrir. Pero que muy posiblemente puede conllevar problemáticas sociales, anexas a la poca disponibilidad de tiempo de sus madres, en el entorno en el que se desenvuelven. Por eso, muchas veces estas mujeres prefieren limitarse a tener pocos recursos y a oportunidades de trabajo flexibles desde su lugar de vivienda o con pocas restricciones para el cuidado de sus hijos. 
Las mujeres consideran que si ellas tuvieran un trabajo que les permitiera además de llevar recursos para su hogar, generar estrategias para su desarrollo personal y familiar, se sentirían más útiles reconocidas dentro de la sociedad, y no como personas que son una carga social y que son menospreciadas por la situación que vivieron antes de llegar a la ciudad.

En relación con las ayudas que mencionan la Ley 387 de 1997 y el Decreto 250 de 2005, para la estabilización socioeconómica, las mujeres refieren que hasta el momento han recibido ayuda humanitaria de emergencia integrada por mercados, hospedaje, menaje o dinero. Pero estas ayudas, que al principio representan un aporte para su estabilización, generan cierto grado de dependencia, por lo cual se debe considerar de vital importancia establecer estrategias que les generen recursos a más largo tiempo no solo en el ámbito asistencial, sino de generación de formas de implementación de mecanismos que permitan su incursión en el trabajo formal. Igualmente, ellas manifiestan que esta ayuda no se recibió debido a que no se solicitó por la tramitología que se requería. Esta situación permite ver que el presupuesto existente para la atención a la población desplazada tiene una mayor inversión en la asistencia inmediata y no en opciones que le permitan a la población la generación de capacidades para el autosostenimiento familiar, y no la dependencia institucional.

En relación con la estrategia planteada por el Gobierno nacional en el Decreto 250 de 2005, en lo que respecta a la generación de ingresos y estabilización socioeconómica con los proyectos productivos, tan solo el $30 \%$ de las mujeres que integran la asociación, ha recibido el aporte del proyecto productivo que establece la normatividad vigente; el 70 \% restante, aunque hace parte de la asociación, se encuentran realizando trámites para el proceso de estructuración de sus propuesta y del cumplimiento de requisitos para la obtención del beneficio. Es importante aclarar que aunque exista la voluntad de las entidades que administran dichos recursos en el municipio, hay diversas limitaciones para el desembolso de recursos en este tema, teniendo en cuenta que el grueso de los recursos se invierte en los programas de atención y no de estabilización de la población desplazada.

Estas mujeres reconocen que al crear empresa están proporcionando herramientas para ellas y para otras mujeres, de estabilización y de garantía de un derecho como es el trabajo, para el mejoramiento de la calidad de vida de muchas personas desplazadas, pero son conscientes de que sin el apoyo del Estado no pueden Ilegar a generar procesos que beneficien en este caso a la asociación y sus integrantes.

Ellas, asimismo, argumentan que esta forma de asociación es una estrategia de productividad entre muchas otras que ellas tienen, como emplearse en almacenes, trabajar en oficios varios, con lo cual pueden tener ingresos que solventen su 
economía familiar, pero que no les permite hacer planes para futuro, sino vivir el día a día. Por lo cual no sienten que su derecho al trabajo digno se esté respetando de manera que les procure situaciones de crecimiento personal y familiar, ni de fortalecimiento de estrategias de superación, de tranquilidad en el medio en el que se desenvuelven, lo que limita su realización como personas y su interacción a nivel familiar y social, afectando igualmente otras facetas como su educación, la vida familiar, el desarrollo integral, su reconocimiento en la sociedad, su ciudadanía, la participación democrática, entre otras.

Las mujeres que no han recibido proyecto productivo (70 \%) hasta el momento, manifiestan que ha sido muy complicada la gestión con entes departamentales y nacionales, incluso con la misma alcaldía se han tornado difíciles e ineficaces las acciones para la consecución de las unidades productiva, ya que el municipio debe recurrir a entes externos para la entrega de incentivos económicos. El porcentaje restante refiere que no cumple con algunos requisitos exigidos, e incluso que por tanta tramitología prefiere no gestionar dicho beneficio de manera individual, sino establecer alianzas para la obtención de recursos que les dé la confianza de generar ingresos. Esto se propone y gestiona a través de la Asociación, con el fin de que se fortalezca de manera óptima la alternativa de generación de ingresos.

Una variante conexa a esta situación es que el monto estipulado para cada una de las mujeres a nivel individual $(\$ 1.500 .000)$ no representa un recurso con el cual se puedan iniciar de forma eficaz actividades para el sostenimiento de una familia. Por lo cual, con este dinero lo que se logra es que ellas continúen en la informalidad y no oportunidades laborales que les permitan superar su estado de vulnerabilidad, y con ello su situación de pobreza.

Además, estas mujeres consideran que el derecho al trabajo implica el reconocimiento de capacidades, habilidades, conocimientos y saberes de cada uno de los sujetos, con el fin de que no solo sea una acción de producción de bienes, sino un crecimiento a nivel personal, en donde ellas sientan que pueden aportar pero, además, que este trabajo se ajuste a sus requerimientos y culturas. El derecho al trabajo para ellas implica el reconocimiento de que son seres emocionales y por ende familiares, y que sus núcleos familiares representan un factor importante en su estabilidad personal, lo que significa que sus trabajos deben permitir que tanto ellas como su entorno próximo compartan situaciones con un nivel suficiente de tranquilidad.

Las mujeres relacionan la garantía del derecho al trabajo con una estabilidad económica que les permita a ellas y a sus familias tener lo necesario para no preocuparse por la satisfacción de sus necesidades primarias. Esta respuesta se debe a la premura que tienen estas mujeres de garantizarles lo necesario a sus familias. En efecto, en el fondo lo que buscan es que tanto ellas como sus hijos 
tengan la garantía de unos ingresos estables y permanentes que se obtienen mediante un trabajo igualmente estable y acorde a las características de cada persona, que les permita su realización personal y sentir que son útiles dentro de una sociedad a la cual pertenecen. El trabajo se convierte para ellas en el "medio a través del cual el hombre, ser inteligente y capaz, puede realizarse a plenitud como persona, como miembro de una familia y como participante de una sociedad" (Mejía, 2013).

\section{Conclusiones}

Luego del trabajo desarrollado con la Asociación Nuevo Comienzo, del municipio de Facatativá, se pueden establecer las siguientes conclusiones de los hallazgos producto de la investigación en torno a la garantía del derecho al trabajo para ellas como mujeres desplazadas:

Las condiciones laborales de las mujeres desplazadas habitantes de Facatativá, cambiaron radicalmente a raíz de su desarraigo. Los resultados de las entrevistas realizadas a las vinculadas a la Asociación "Nuevo comienzo", muestran que ellas Ilegaron a centros poblados, o zona urbana, a engrosar las listas de desempleados, o en el mejor de los casos, de trabajadores informales, con condiciones peores que los pobres crónicos del municipio. Con el desplazamiento se transformaron sus capacidades de generación de ingresos, pasando de ser mujeres que se dedicaban a la agricultura o al apoyo familiar en labores del campo, a habitantes de la ciudad con bajos niveles de educación, que recurren a los servicios de los entes oficiales y que se "rebuscan" lo del diario para poder sobrevivir.

La Corte Constitucional, en el auto 008 de 2009, luego de más de diez años de las primeras iniciativas de estudio y análisis de la situación de la población desplazada, continúa recalcando que existe carencia de una política pública coherente para afrontar el problema de la estabilización socioeconómica de la población desplazada. Este vacío de acciones y compromisos institucionales, es reconocido por la mayor parte de los actores estatales y sociales que trabajan en el tema, sin que se Ilegue a asumir acciones concretas y que denoten resultados óptimos para mejorar las condiciones de las mujeres en esta situación, como es el caso de Facatativá, en donde, pese a reconocerse la falencia de programas enfocados a mujeres desplazadas, no se da un manejo claro de esta política pública. Para una reparación integral de estas mujeres, se debe contemplar una asistencia humanitaria de emergencia, atención psicosocial, formación, asesoría en el proyecto productivo con énfasis en sus conocimientos y habilidades y el seguimiento y fortalecimiento del mismo, además del acceso a servicios básicos como salud, educación y vivienda.

Con el fin de que los proyectos productivos sean integrales y propendan la garantía de un derecho como es el trabajo, deben además de generar ingresos para las mujeres en situación de desplazamiento, permitir que ellas sientan que están 
recuperando el control de su vida, su rol y papel en la familia y en la sociedad, y la posibilidad de generar estabilidad representada en unión familiar, para recuperar parte de su dignidad perdida en el desplazamiento.

Igualmente, aunque la normatividad de atención a la población desplazada viene implementándose desde hace más de dos décadas, Facatativá hasta ahora está iniciando con la articulación y formulación de acciones para la atención integral de esta población. Por lo cual no referencia ninguna atención a nivel diferencial para las mujeres habitantes, ni para grupos poblacionales específicos en el municipio. Con esto evidencia que a pesar de los avances que se han dado en el tema del reconocimiento de la problemática de violación de derechos de las personas en situación de desplazamiento del municipio, aún se ve escasa la articulación entre sectores, para el cumplimiento de los autos de seguimiento que la Corte Constitucional ordena desarrollar en todo el territorio colombiano.

Ahora, en el tema del derecho al trabajo como garantía de bienestar y desarrollo para la mujer desplazada de Facatativá, tiene especial importancia en el momento insertarse en el ámbito de la ciudad, teniendo en cuenta que es la forma la que estas mujeres recurren para alcanzar un grado de estabilidad en el momento en que se asumen como dueñas de su vida, y potenciadoras de la vida de sus familiares. En estos casos, el trabajo representa para ellas el recurso primario para alcanzar una vida digna, mediante el desarrollo de sus capacidades, pero también como el movilizador de recursos para el empoderamiento y el descubrimiento de nuevas habilidades y capacidades escondidas que pueden llegar a aportar en el desarrollo de su calidad de vida y en el alcance de nuevos niveles de bienestar y movilización social.

El hecho del desplazamiento y del desempleo al que se ven enfrentadas las mujeres en Facatativá, las dificultades que conlleva la ciudad y la necesidad de una acción estatal de apoyo, no hacen imposible su desempeño, es decir, que esto no implica únicamente desventajas. El ejercicio reconocido de su autoridad, su labor más autónoma, su desempeño laboral en ámbitos diferentes, pueden reidentificar sus potencialidades como mujer, optimizar en ella y sus familias recursos y efectos constructivos para ella y la comunidad en la cual se encuentra.

Más allá de los planes y mandatos gubernamentales que contribuyen a incorporar la atención al problema del desplazamiento en las agendas de las diferentes instituciones, es evidente que se requiere de una profunda sensibilización al respecto. La percepción que se tiene de que el Estado no está cumpliendo con sus obligaciones al ser garante de los derechos de sus habitantes, específicamente en el tema de oportunidades laborales, hace que cada vez se tenga más desconfianza y resentimiento por parte de la población desplazada, que en el momento de ser desarraigada, uno de los derechos que espera ver garantizado con mayor énfasis es el del trabajo. 
La prioridad a la cual debe apuntar la sociedad colombiana es a apostar por facilitar y apoyar los procesos relativos al nuevo comienzo de la población desplazada, pero se requiere de la voluntad estatal para que estos esfuerzos se vean materializados en hechos en los cuales las mujeres desplazadas puedan acceder a trabajos u opciones laborales que les permitan trascender el lugar de vulnerabilidad y superar sus limitaciones mediante una actividad que les posibilite su desarrollo, acorde a sus capacidades y opciones.

Aunque la dimensión de género ha sido reconocida a nivel internacional y nacional como esencial para lograr programas de atención para la población desplazada, tal consideración está siendo tomada inadvertida por los agentes institucionales al generalizar políticas en momentos específicos. Ello se debe, entre otras cosas, a las necesidades apremiantes de inversión, que definen prioridades inmediatas y falta de capacitación y experiencia de quienes se encargan del tema.

Es así como al articular las acciones desarrolladas por la Administración municipal y a través del Consejo Municipal de Justicia Transicional, y al conocer las características y expectativas de las mujeres desplazadas que buscan opciones de sostenimiento de su núcleo familiar, se encuentra una brecha entre lo que necesitan y desean las mujeres y lo que en verdad se está realizando por ellas, debido a la presión de entes nacionales de control.

Ellas esperan que una forma para que se les garantice el derecho al trabajo sea que la asociación pueda sostenerse y generar capacidad de involucrarse en el campo comercial, para que puedan establecerse formas de estabilización socioeconómica y desarrollo para cada una de las integrantes. También consideran que más allá de la vinculación laboral, las mujeres desplazadas requieren de un trabajo que garantice otros derechos, pero que igualmente esté dentro de sus características y condiciones familiares y sociales para mantener su cultura, costumbres, hábitos y, sobre todo, para que puedan continuar ocupándose de su familia como lo venían haciendo antes de su desplazamiento, y seguir con su crecimiento personal y familiar.

\section{Referencias}

Agencia Presidencial de Acción Social y Cooperación Internacional. (2010). Estadísticas Desplazados. Recuperado de http://www.acnur.org/t3/recursos/ publicaciones/publicaciones/?eID = dam_frontend_push\&docID =13012

Alcaldía de Bogotá. (2005). Decreto 250 2005. Por el cual se expide el Plan Nacional para la Atención Integral a la Población Desplazada por la Violencia y se dictan otras disposiciones. Recuperado de http://www. alcaldiabogota.gov.co/ sisjur/normas/Norma1.jsp?i = 15909 
Alcaldía Municipal de Facatativá. (2011). Política pública social para las familias facatativeñas y sus integrantes con y sin discapacidad.

Alcaldía Municipal de Facatativá. (2013). Plan de atención territorial para la prevención, asistencia, atención y reparación integral a las víctimas del conflicto armado en el municipio de Facatativá.

Codhes \& Unicef. (1999). Un país que huye: desplazamiento y violencia en una nación fragmentada. Bogotá: s.n.

Codhes \& Unicef. (2013). Un país que huye: desplazamiento y violencia en una nación fragmentada. Bogotá: s.n.

Congreso de la República de Colombia (1997). Ley 387 de 1997. Recuperado de http://www.alcaldiabogota.gov.co/sisjur/normas/Norma1.jsp?i $=340$

Corte Constitucional. (2009). Auto 098 de 2009. Recuperado de http:// www.corteconstitucional.gov.co

González, M. (2002). Desterrados, el desplazamiento forzado en Colombia. Médicos sin Fronteras. España. Recuperado de http://www.reliefweb.int/library/ documents/2002/msf-col-31may.pdf

Kemmis, S. \& Mac, T. (1998). Como planificar la investigación-acción. Barcelona: Laertes.

Mejía, A. (2013). El trabajo, derecho humano fundamental. S.I.: Federación de periodistas de América Latina y el Caribe.

Meertens, D. (2000). Ensayos sobre tierra, violencia y género. (2 ed.). Bogotá: Universidad Nacional de Colombia.

Observatorio de Derechos Humanos de Mujeres en Colombia. (2000). Las invisibles. Desplazamiento y política pública. Informe de derechos humanos de las mujeres. Bogotá: ODHMC.

Osorio, F. (1999). La violencia del silencio: desplazados del campo a la ciudad. Bogotá: Consultoría para los Derechos Humanos y el Desplazamiento, Universidad Javeriana.

Rodríguez, G. (1998). Métodos de investigación cualitativa. Bogotá: Dimensión Educativa.

Segura, N. \& Meertens, D. (1997). Desarraigo, género y desplazamiento interno en Colombia. Rev. Nueva Sociedad, (148). 